\title{
Interleukin-31, Interleukin-31RA, and OSMR Expression Levels in Post-burn Hypertrophic Scars
}

\begin{abstract}
Mi Young Lee · Eun Shin ${ }^{1}$
Hyunchul Kim ${ }^{1}$. In Suk Kwak ${ }^{2}$

Younghee $\mathrm{Choi}^{3}$

Department of Pathology, Hallym University College of Medicine, Chuncheon; ' 1 Department of Pathology, Hallym University Dongtan Sacred Heart Hospital, Hwaseong; '2Department of Anesthesiology and Pain Medicine, Hallym University Hangang Sacred Heart Hospital, Seoul; ${ }^{3}$ Department of Pathology, Hallym University Hangang Sacred Heart Hospital, Research Institute for Complementary and Alternative Medicine, Seoul, Korea
\end{abstract}

Received: June 11, 2018

Revised: July 29, 2018

Accepted: August 3, 2018

\section{Corresponding Author}

Younghee Choi, MD

Department of Pathology, Hallym University

Hangang Sacred Heart Hospital, 12 Beodeunaru-ro

7-gil, Yeongdeungpo-gu, Seoul 07247, Korea

Tel: $+82-2-2639-5575$

Fax: $+82-2-3399-1741$

E-mail: yhchoi@hallym.or.kr

\begin{abstract}
Background: Although several studies have shown the role of interleukin-31 (IL-31) and its receptors in inducing pruritus in certain skin disorders, knowledge of its role in post-burn hypertrophic scars is insufficient. Therefore, the histopathological expression levels of IL-31, IL-31 receptor alpha (IL-31RA), and oncostatin M receptor (OSMR) in post-burn hypertrophic scar tissues were investigated and compared with normal tissue expression levels. Methods: Samples of hypertrophic scar tissue were obtained from 20 burn patients through punch biopsy. Normal samples were obtained from areas adjacent to the burn injury site of the same patients. Samples were placed in $10 \%$ neutral buffered formalin, embedded in paraplast, and processed into serial 5 - $\mu \mathrm{m}$ sections. Immunohistochemistry results were semi-quantitatively evaluated for IL-31, IL-31RA, and OSMR. By hematoxylin and eosin staining, epidermal and dermal thickness were assessed with a microscope and digital camera. Intensities were rated on a scale of 1 to 4 . Results: Percentages for IL31, IL-31RA, and OSMR in the epidermal basal layer cell cytoplasm were significantly greater in the burn scar tissue compared to normal skin, as well as the dermal and epidermal thickness $(p<$ .05). There was a significant difference in IL-31 epidermal basal layer intensity in burn scar tissue compared to normal skin $(p<.05)$. Besides the OSMR basal layer intensity, IL-31 and IL-31RA intensities between the burn scar and normal tissues were not significant. However, correlations were significant, indicating that the greater the infiltration percentage, the higher the intensity $(p<$ .05). Conclusions: IL-31, IL-31RA, and OSMR expression levels are increased in hypertrophic scars compared with normal tissue.
\end{abstract}

Key Words: Burns; Cicatrix; Interleukin-31; IL31RA protein; OSMR protein
Burns are a severe and traumatic injury to the skin. Although approximately 300,000 deaths still occur annually due to burns, mortality rates have been reduced due to advancements in acute burn care. Unfortunately, burn recovery remains a challenging process due to abnormal scarring of the skin, which has an adverse impact on quality of life. ${ }^{1}$ Following a burn injury, the incidence of hypertrophic scar development is reported to be as high as $77 \%{ }^{2}$

Normal wound healing of the human skin occurs through a balance of deposition and removal of structural proteins and glycoproteins at an optimal speed for the development of a healthy, functional scar. ${ }^{3}$ However, this balance is rarely maintained in post-burn hypertrophic scars, causing an over-growth of collagen in the dermis, proteoglycans, fibronectin, and tissue water. $^{4-7}$ Dermal fibroblasts may have a large influence on increased matrix production, through continuously high amounts of fibrogenic cytokines and other changes in dermal structure. ${ }^{8-10}$ The thin collagen fibers with increased synthesis and crosslinks found in hypertrophic scars result in scars that are raised, thick, red, firm, and do not grow beyond the original wound margins. ${ }^{11}$ Many burn survivors who develop hypertrophic scars complain of functional disability, cosmetic dysfunction, pain, and itchiness, also known as pruritus. ${ }^{2}$ For many patients, the most distressing symptom of hypertrophic scar formation is the associated pruritus. ${ }^{12}$

Pruritus affects burn survivors' quality of life by causing sleep disturbances, daily activity impairment, and psychological problems. Pruritus induces scratching, which can lead to wound infections and disrupt the proper wound healing process. ${ }^{13}$ After a burn injury, the wound healing process may last up to a year. Wound healing consists of three phases: early inflammatory, intermediate proliferative, and late remodeling. ${ }^{14}$ Acute itching eventually disappears in the remodeling phase. Chronic itching 
occurs at relatively low intensities and is associated with injury depth, although it may persist for more than 2 years. ${ }^{15}$ Postburn pruritus is regarded as a complex disease that is combined with pruritogenic, neuropathic, neurogenic, and psychogenic mechanisms, especially in chronic cases. ${ }^{16}$ Various existing treatment methods are not completely satisfactory since the exact mechanism of post-burn pruritus is unclear. ${ }^{14}$

Interleukin (IL)-31 appears to have a role in pruritus induction in disorders such as atopic dermatitis (AD) and prurigo nodularis. ${ }^{17-19} \mathrm{IL}-31$ is a fairly novel cytokine derived from T-cells and is included in the IL-6 cytokine family. It signals through a heterodimeric receptor composed of IL-31 receptor alpha (IL-31RA) and Oncostatin M receptor (OSMR).

Patients who commonly experience pruritus are those affected by $A D$. Studies have shown an association between pruritic diseases and IL-31. Sonkoly et al. ${ }^{20}$ examined human IL-31 and its role in pruritic and non-pruritic inflammatory skin diseases. ${ }^{20}$ The study found significant overexpression of IL-31 in atopic skin with pruritus compared to psoriasis, which rarely itches and is thus considered a non-pruritic inflammatory disease. The highest levels of IL-31 were detected in prurigo nodularis, an intense form of pruritic chronic inflammation of the skin. In vivo, rapid production of IL-31 was reported with the staphylococcal superantigen in atopic subjects. Therefore, when IL-31 levels are elevated in lesions, they may amplify the inflammation of the skin through chemokine induction, subsequently causing T-cell recruitment. As a result, IL-31 may be produced by activated skin-infiltrating $\mathrm{T}$ cells, worsening the inflammation and pruritus. ${ }^{20}$

Murine neuronal tissue studies have found that IL-31RA plays a significant role in itching and that OSMR is also recruited by IL-31. ${ }^{21,22}$ According to Le Saux et al., ${ }^{23} \mathrm{IL}-31$ needs to bind to IL-31RA before OSMR because of a conformational transformation that occurs in IL-31. This change is essential for the binding of IL-31 to OSMR. ${ }^{23}$ Therefore, IL-31RA and OSMR should also be included in the discussion on pruritus.

Based on the reports of elevated IL-31 and its receptors in the previously mentioned pruritic conditions, potentially important but unidentified roles of IL-31, IL-31RA, and OSMR in the development of pruritus in post-burn hypertrophic scars may exist. Although several studies have demonstrated the role of IL-31 in inducing pruritus in certain skin disorders, knowledge of its role in post-burn hypertrophic scars is insufficient. This appears to be the first study to examine this cytokine and its receptors in post-burn hypertrophic scars. Therefore, the purpose of this study was to examine the expression levels of IL-31, IL-31RA, and OSMR in hypertrophic scar tissue versus normal tissue.

\section{MATERIALS AND METHODS}

\section{Patient selection}

Twenty samples of hypertrophic burn scars were obtained from patients who had visited the Hallym University Hangang Sacred Heart Hospital in South Korea. Subjects were included in the study if they were at least seven years of age at the time of examination. Subjects were excluded if they (1) had a pre-existing disease known to frequently cause pruritus, such as chronic systemic or dermatologic disease, (2) were pregnant, (3) were unable to specifically describe their pruritus, (4) were on concurrent systemic medications that may affect their pruritic symptoms such as antihistamines, morphine, or systemic steroids, (5) had any psychotic diseases, (6) had cancer, (7) had an active infection, or (8) had been treated with immunomodulators, UV irradiation, or hydrogen peroxide within three months before surgery. All subjects provided informed consent. The protocols of this study were approved by Hallym University Hangang Sacred Heart Hospital Institutional Review Board (IRB approval No. 2011-186).

\section{Histopathological analysis}

Skin samples were obtained through punch biopsy $(6 \mathrm{~mm})$ during surgery from twenty patients between 2011 and 2012. Control tissue samples were obtained from non-burned skin areas adjacent to the burn injury site from the same patients. Tissue samples from hypertrophic scars were taken from the burn lesions of the same patients. The tissue samples were placed in $10 \%$ neutral buffered formalin for 18 hours. Paraplast (Sigma-Aldrich, St. Louis, MO, USA) was used for paraffin embedding. Serial sections $5-\mu \mathrm{m}$ in thickness were processed. ${ }^{24}$ The IL-31 antibody (Novus Biologicals, Littleton, CO, USA), IL-31RA antibody (Abnova, Taipei, Taiwan), and OSMR antibodies (Novus Biologicals) were used for staining purposes and sections were assessed by a pathologist. Immunohistochemistry results were semi-quantitatively evaluated for IL-31, IL-31RA, and OSMR based on the estimated epidermal positive basal cell percentage. Cells were counted in the stroma using a built-in $10 \times 10$ grid within the Nikon microscope (Plan-Apo, Nikon, Tokyo, Japan) with each section measuring $25 \mu \mathrm{m}(0.025 \mathrm{~mm})$ at $\times 400 \mathrm{mag}$ nification and the upper edge of the grid placed at the epidermal junction. ${ }^{25}$ Three areas with the greatest density of inflammatory cells with the most distinct inflammation were counted per visual field and the cells were regarded as either immunoreactive or non-immunoreactive. ${ }^{19}$ The IL-31RA epidermis, IL-31 epidermis basal layer, and OSMR epidermis basal layer staining intensities 
were rated as 1 when the positivity could be seen at 400, 2 at 200, 3 at 100, and 4 at 40-fold magnification with use of a Nikon microscope (Plan-Apo) with a digital camera (Nikon, DS-Ri2, Nikon digital SLR camera FX-format CMOS sensor optimized for microscopy). ${ }^{24}$ One pathologist and one dermatologist assessed the epidermal thickness, dermal thickness, and IL-31, IL-31RA, and OSMR infiltration through hematoxylin eosin staining through use of a Nikon microscope (Plan-Apo) with a digital camera (Nikon, DS-Ri2, Nikon digital SLR camera FX-format CMOS sensor optimized for microscopy), and the average values were obtained.

\section{Statistical analysis}

SPSS ver. 21.0 for Windows (IBM Corp., Armonk, NY, USA) was used for statistical analysis. Normal skin and burn scar tissue comparisons were performed using the paired t test and the Wilcoxon signed-rank test. Pearson and Spearman tho was used to examine the correlation between IL-31, IL31-RA, and OSMR percentages and intensities. Values were regarded as significant if the $\mathrm{p}$-value was $<.05$.

\section{RESULTS}

This study included tissue samples from twenty subjects. The characteristics of the burn subjects are presented in Table 1.

Comparison of burn scar and normal skin tissue characteristics are presented in Table 2. There was a significant difference in dermal thickness in burn scar tissue compared with normal skin $(4,826.85 \pm 1,955.34 \mu \mathrm{m}$ and 1,809.50 $\pm 745.54 \mu \mathrm{m}$, respectively; $\mathrm{p}<.001)$ and the epidermal thickness was signifi- cantly thicker in the burn scar tissue compared with normal skin $(5,112.25 \pm 2,522.42 \mu \mathrm{m}$ vs. $1,729.88 \pm 806.55 \mu \mathrm{m}$, respectively; $\mathrm{p}<.001)$. The epidermal basal layer percentage of IL-31 was significantly greater in burn scar tissue compared with normal skin (22.4\% and $12.7 \%$, respectively; $\mathrm{p}<.001)$ (Fig. 1). However, there was no significant difference in IL-31 epidermal basal layer intensity in burn scar tissue compared with normal skin ( $p>.05)$. The IL-31RA epidermal percentage was significantly greater in burn scar tissue compared with normal skin $(29.8 \%$ and $23.9 \%$, respectively; $\mathrm{p}<.001)$ (Fig. 1). The comparison of IL-31, IL-31RA, and OSMR percentage levels between control and scar tissue is shown in Fig. 2. There were no significant differences in IL-31 epidermis basal layer intensity ( $>$ >05). The OSMR epidermal basal layer cytoplasm percentage was greater in burn scar tissue compared with normal skin $(46.50 \%$

Table 1. Characteristics of burn subjects $(n=20)$

\begin{tabular}{|c|c|}
\hline Variable & Value \\
\hline Sex (male:female) & $14: 6$ \\
\hline Side (right:left) & $10: 10$ \\
\hline Age at time of examination (yr) & $27.53 \pm 18.73$ \\
\hline Age at burn incident (yr) & $18.04 \pm 20.05$ \\
\hline Scar age (mo) & $46.42 \pm 97.97$ \\
\hline No. of burn sites & $\begin{array}{l}\text { Both arms (4), head (11), both legs (1), } \\
\text { foot (4) }\end{array}$ \\
\hline No. of burn sources & $\begin{array}{l}\text { Hot water (8), friction (1), iron (2), } \\
\text { flame (4), electricity (1), chemical (1), } \\
\text { steam (3) }\end{array}$ \\
\hline No. of burn treatments & $\begin{array}{l}\text { CT (7), STSG (5), FTSG (5), } \\
\text { STSG+Alloderm (3) }\end{array}$ \\
\hline
\end{tabular}

Age at time of examination and scar age values are presented as mean \pm standard deviation.

CT, conservative treatment; STSG, superficial thickness skin graft; FTSG, full-thickness skin graft.

Table 2. Histopathological comparison of normal tissue and scar tissue characteristics

\begin{tabular}{|c|c|c|c|c|}
\hline Variable & Normal tissue $(n=20)$ & Scar tissue $(n=20)$ & $t / z$ & p-value \\
\hline Exam age (yr) & $21.80 \pm 18.10$ & $21.80 \pm 18.10$ & -1.000 & .325 \\
\hline Sex (male:female) & $14: 6$ & $14: 6$ & & \\
\hline Burn age (yr) & & $10.20 \pm 16.36$ & & \\
\hline Scar age (mo) & & $115.60 \pm 145.15$ & & \\
\hline Dermal thickness $(\mu \mathrm{m})$ & $1,809.50 \pm 745.54$ & $4,826.85 \pm 1,955.34$ & -7.802 & $<.001^{* \star *}$ \\
\hline Epidermal thickness $(\mu \mathrm{m})$ & $114.05 \pm 30.91$ & $174.10 \pm 51.56$ & -6.528 & $<.001^{* * *}$ \\
\hline IL-31 epidermis basal layer percentage (\%) & $12.00 \pm 12.39$ & $17.50 \pm 16.81$ & -3.425 & $<.001^{* * *}$ \\
\hline IL-31 epidermis basal layer intensity & & & -1.941 & .052 \\
\hline IL-31RA epidermis percentage (\%) & $38.50 \pm 24.54$ & $56.00 \pm 28.72$ & -4.148 & $<.001^{* * *}$ \\
\hline IL-31RA epidermis intensity & & & -1.694 & .900 \\
\hline OSMR epidermis basal layer cytoplasm (\%) & $25.00 \pm 17.91$ & $46.50 \pm 27.96$ & -4.747 & $<.001^{* * *}$ \\
\hline OSMR epidermis basal layer intensity & & & -2.841 & $.005^{* *}$ \\
\hline No. of mast cells & $4.17 \pm 3.20$ & $8.00 \pm 8.00$ & -2.504 & $.022 *$ \\
\hline
\end{tabular}

Values are presented as mean \pm standard deviation.

$\%$, percentage of infiltration; Intensity, intensity of the microscopic expression.

Significant ${ }^{*} p<.05,{ }^{* *} p<.01,{ }^{* * *} p<.001$. 

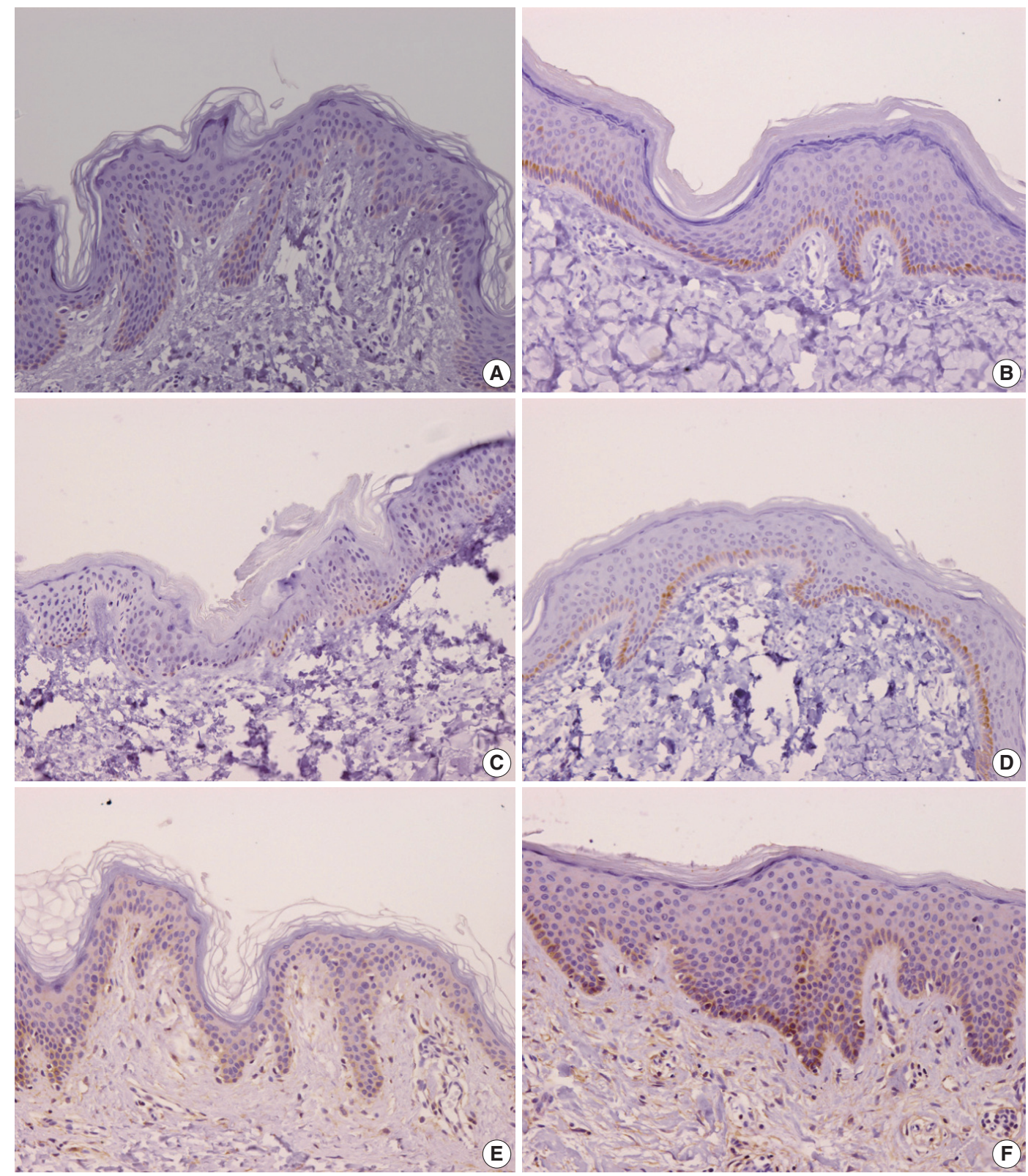

Fig. 1. (A) Interleukin 31 (IL-31) control. (B) IL-31 scar. (C) IL-31 receptor alpha (IL-31RA) control. (D) IL-31RA scar. (E) Oncostatin M receptor (OSMR) control. (F) OSMR scar. IL-31, IL-31RA, and OSMR infiltration.

and $25.00 \%$, respectively; $\mathrm{p}<.001$ ) (Fig. 1). There was also a significant difference in OSMR epidermis basal layer intensity in burn scar tissue compared with normal skin $(\mathrm{p}<.005)$. Pearson and Spearman rho analyses showed that the correlations between the percentages and intensities of IL-31, IL-31RA, and OSMR in burn scar tissue were significant $(\mathrm{p}<.05)$, indicating that the greater the infiltration percentage, the higher the intensity, based on a scale of 1 to 4 (Table 3).

There was also a significant difference in the number of mast cells, which was greater in burn scar tissue compared with normal $\operatorname{skin}(\mathrm{p}<.05)($ Table 2$)$.

\section{DISCUSSION}

The objective of this study was to examine the expression of IL-31, IL-31RA, and OSMR in hypertrophic scar tissue and compare the results with those from normal tissue. IL-31 is a Tcell cytokine which acts through a heterodimeric receptor such IL-31RA and OSMR, which are expressed by epithelial cells. ${ }^{26}$

Our study has found that IL-31, IL-31RA, and OSMR are 
expressed by epidermal basal cells from both normal and burn scar tissue samples. However, IL-31 and IL-31RA expression was significantly higher in the burn scar epidermal basal cells $(\mathrm{p}<$ .001) compared with normal skin tissue. The OSMR epidermal basal layer cytoplasm percentage was also significantly greater than in normal skin. Our findings are relatable to previous studies that have found greater levels of IL-31 and its receptors in subjects with various pruritic skin conditions compared with non-pruritic and normal skin. ${ }^{17-20,23}$ Nobbe et al ${ }^{19}$ reported that the majority of the immunoreactivity stainings for IL-31RA and OSMR were cytoplasmic staining patterns.

Cutaneous T-cell lymphoma patients also commonly suffer from pruritus and have recently been found to have elevated IL31 expression in the epidermis and dermis and increased IL31RA and OSMR expression in the epidermis only. ${ }^{27}$

It appears that IL-31 and its receptors have their respective roles in pruritus induction. IL-31 is postulated to stimulate the keratinocytes and infiltrating cells to release other mediators

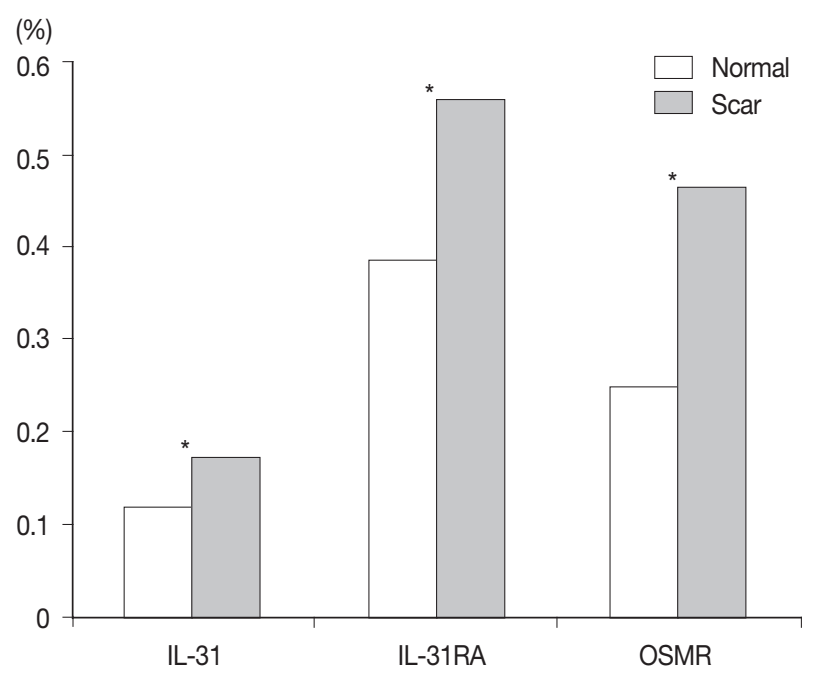

Fig. 2. Comparison of interleukin 31 (IL-31), IL-31 receptor alpha (IL-31RA), and oncostatin M receptor (OSMR) percentage values between the normal and scar tissue $(n=20) .{ }^{*} p<.05$. involved in the induction of pruritus. Moreover, IL-31 appears to cause pro-inflammatory cytokines to be released from macrophages, eosinophils, and monocytes. ${ }^{26,28}$

Expression of IL-31RA and OSMR has been found in keratinocytes and the dorsal root ganglia, which are the locations where the cutaneous sensory neuron soma reside and their sensory fibers are directed towards the skin. ${ }^{29}$ These sensory neurons may be involved in the itch sensation and are thought to be stimulated by IL-31. IL-31 may serve as a possible connection between the immune and sensory nervous system. ${ }^{30}$ Therefore, although the presence of elevated IL-31 and its relation to pruritus is significant, the roles of IL-31RA and OSMR should not be neglected and should be taken into consideration in the discussion of pruritus.

This study found that burn scar thickness and epidermal thickness was significantly increased compared with normal tissue. When a burn injury occurs on the skin, the skin barrier function is damaged or destroyed. ${ }^{31}$ Similarly, for patients with $\mathrm{AD}$, the skin-barrier function is most commonly impaired, indicating that the epithelial defense system serves a significant role in the pathogenesis of $\mathrm{AD} .^{32}$ When the skin barrier is altered or damaged in $\mathrm{AD}$ patients, this is partially associated with the distribution of the stratum corneum liquid composition, which allows harmful substances to penetrate cutaneously and subsequently signals for proliferation and differentiation of the epidermis. ${ }^{31}$ Singh et al. ${ }^{33}$ found that intradermal injection of recombinant mouse IL-31 (rIL-31) produced epidermal thickness and that elevated levels of IL-31 by T cells subsequently induced thickening of the epidermis and inflammatory infiltrates. ${ }^{33}$

There was no significant difference in intensity levels for all variables, except for the OSMR basal layer intensity. This discrepancy may be attributed to the small sample size, but could show significance in future studies with larger sample sizes.

Although this study did not specifically look for pruritus in those with hypertrophic scars, the results show characteristics similar to pruritic skin conditions, such as $\mathrm{AD}$, in which there

Table 3. Correlation between IL-31RA, IL-31, OSMR percentage (Pearson) and intensity (Spearman rho) in burn scar ( $\mathrm{n}=20)$

\begin{tabular}{|c|c|c|c|c|c|c|}
\hline & $\begin{array}{c}\text { IL-31RA } \\
\text { epidermis (\%) }\end{array}$ & $\begin{array}{l}\text { IL-31RA epidermis } \\
\text { intensity }\end{array}$ & $\begin{array}{c}\text { IL-31 epidermis } \\
\text { basal (\%) }\end{array}$ & $\begin{array}{l}\text { IL-31 epidermis } \\
\text { basal intensity }\end{array}$ & $\begin{array}{c}\text { OSMR epidermis } \\
\text { basal cytoplasm (\%) }\end{array}$ & $\begin{array}{c}\text { OSMR epidermis } \\
\text { basal intensity }\end{array}$ \\
\hline IL-31RA epidermis \% & 1 & $0.745^{* * *}$ & $0.534^{*}$ & $0.566^{* *}$ & $0.545^{*}$ & $0.447^{*}$ \\
\hline IL-31RA epidermis intensity & & 1 & $0.675^{\star *}$ & $0.834^{* * *}$ & $0.641^{* *}$ & $0.597^{* *}$ \\
\hline IL-31 epidermis basal \% & & & 1 & $0.953^{* * *}$ & $0.786^{* * *}$ & $0.650^{* *}$ \\
\hline IL-31 epidermis basal intensity & & & & 1 & $0.808^{* * *}$ & $0.683^{* *}$ \\
\hline OSMR epidermis basal cytoplasm & & & & & 1 & $0.814^{* * *}$ \\
\hline
\end{tabular}

Intensity rated as 1 when the positivity could be seen at 400, 2 at 200, 3 at 100, and 4 at 40-fold magnification with use of a Nikon microscope with a digital camera. 1=weak intensity, $4=$ strong intensity. The greater the infiltration percentage, the higher the intensity based on a scale of 1 to 4.

IL-31, interleukin 31; IL-31RA, IL-31 receptor alpha; OSMR, oncostatin M receptor.

${ }^{*} p<.05,{ }^{* *} p<.01,{ }^{* * *} p<.001$. 
are significantly greater IL-31, IL-31RA, and OSMR expression levels in the skin.

There was no significant difference in intensities between the control and burn scar tissues, aside from the OSMR basal layer intensity. However, Pearson and Spearman rho results showed significant correlations between infiltration percentages and intensities in burn scar tissues, where the greater the percentage of infiltration, the greater the grade in intensity, based on the scale of 1 to 4 . As stated earlier, the IL-31RA epidermis, IL-31 epidermis basal layer, and OSMR epidermis basal layer staining intensity was rated as 1 when the positivity could be seen at 400, 2 at 200, 3 at 100, and 4 at 40-fold magnification with use of a Nikon microscope. In this case, an intensity grade of 4 is equal to 40-fold magnification; this indicates that the intensity is strong with low magnification because if the percentage of infiltration is high enough, a smaller amount of magnification is required to observe the infiltration through the microscope.

The mean value of the mast cells was significantly greater in the burn scar compared with the normal tissue samples. This finding may be significant for several reasons. Antimicrobial peptide proteins (AMPs), such as human $\beta$-defensins (hBDs), provide innate immunity and defense against microbial invasion, which is a common risk factor with burn injury, and are formed in the deep portions of burned skin. ${ }^{34,35}$ Mast cells are located within the dermis and have been found to be another source of IL-31. ${ }^{34}$ AMPs have been found to cause mast cells to release IL-31 mRNA, and may lead to protein production and release. ${ }^{34}$ Niyonsaba et al..$^{36}$ has also stated that mast cells are involved in the pathological process of other disorders of the skin in which AMP concentrations are enhanced. ${ }^{36}$ In the case of wounding and lichen planus, direct contact between skin-derived AMPs and mast cells occurs, which subsequently activates due to basal membrane impairment between the dermis and epidermis. Sites of infection and inflammation show elevated amounts of hBDs and leucine-leucine 37-amino acid peptide (LL-37) in the human epithelium. LL-37 is induced in the keratinocytes of humans during contact dermatitis ${ }^{37}$ and hBDs may contribute to skin inflammatory responses by causing mast cells to secrete IL-31 along with other factors that are pruritogenic. These findings may support the link between increased IL-31 levels and postburn hypertrophic scar pruritus in the present study.

This study had some limitations. The sample size was small and subject complaints of pruritus were not fully assessed. In addition, no other techniques were used to confirm our findings. However, this study has shown that there are pathological similarities between post-burn pruritus and other skin diseases known to cause pruritus, such as $\mathrm{AD}$, prurigo nodularis, and cutaneous T-cell lymphoma, all of which exhibit increased expression levels of IL-31.

Therefore, the findings of this study may enlighten the understanding of pruritic events occurring in post-burn hypertrophic scars. Further studies with larger sample sizes that investigate the relationship between IL-31 and receptor expression levels with subjective and objective measurements of pruritus are warranted.

\section{ORCID}

Mi Young Lee: https://orcid.org/0000-0002-5171-6370

\section{Conflicts of Interest}

No potential conflict of interest relevant to this article was reported.

\section{Acknowledgments}

This research was supported by the Hallym Univesirty Medical Center Research Fund (01-2011-28).

\section{REFERENCES}

1. Amini-Nik S, Yousuf Y, Jeschke MG. Scar management in burn injuries using drug delivery and molecular signaling: current treatments and future directions. Adv Drug Deliv Rev 2018; 123: 135-54.

2. Bombaro KM, Engrav LH, Carrougher GJ, et al. What is the prevalence of hypertrophic scarring following burns? Burns 2003; 29: 299-302.

3. Szulgit G, Rudolph R, Wandel A, Tenenhaus M, Panos R, Gardner $H$. Alterations in fibroblast $\alpha 1 \beta 1$ integrin collagen receptor expression in keloids and hypertrophic scars. J Invest Dermatol 2002; 118: 409-15.

4. Knapp TR, Daniels RJ, Kaplan EN. Pathologic scar formation: morphologic and biochemical correlates. Am J Pathol 1977; 86: 47-70.

5. Swann DA, Garg HG, Jung W, Hermann H. Studies on human scar tissue proteoglycans. J Invest Dermatol 1985; 84: 527-31.

6. Shetlar MR, Dobrkovsky M, Linares H, Villarante R, Shetlar CL, Larson DL. The hypertrophic scar. Glycoprotein and collagen components of burn scars. Proc Soc Exp Biol Med 1971; 138: 298-300.

7. Babu M, Diegelmann R, Oliver N. Fibronectin is overproduced by keloid fibroblasts during abnormal wound healing. Mol Cell Biol 1989; 9: 1642-50.

8. Murray JC. Keloids and hypertrophic scars. Clin Dermatol 1994; 12: $27-37$. 
9. McCauley RL, Chopra V, Li YY, Herndon DN, Robson MC. Altered cytokine production in black patients with keloids. J Clin Immunol 1992; 12: 300-8.

10. Ghahary A, Shen YJ, Scott PG, Gong Y, Tredget EE. Enhanced expression of mRNA for transforming growth factor-beta, type I and type III procollagen in human post-burn hypertrophic scar tissues. J Lab Clin Med 1993; 122: 465-73.

11. Xue M, Jackson CJ. Extracellular matrix reorganization during wound healing and its impact on Abnormal Scarring. Adv Wound Care (New Rochelle) 2015; 4: 119-36.

12. Choi YH, Kim KM, Kim HO, Jang YC, Kwak IS. Clinical and histological correlation in post-burn hypertrophic scar for pain and itching sensation. Ann Dermatol 2013; 25: 428-33.

13. Scott JR, Muangman P, Gibran NS. Making sense of hypertrophic scar: a role for nerves. Wound Repair Regen 2007; 15 Suppl 1: S27-31.

14. Parnell LK, Nedelec B, Rachelska G, LaSalle L. Assessment of pruritus characteristics and impact on burn survivors. J Burn Care Res 2012; 33: 407-18.

15. Profyris C, Tziotzios C, Do Vale I. Cutaneous scarring: Pathophysiology, molecular mechanisms, and scar reduction therapeutics Part I. The molecular basis of scar formation. J Am Acad Dermatol 2012; 66: $1-10$.

16. Van Loey NE, Bremer M, Faber AW, Middelkoop E, Nieuwenhuis MK. Itching following burns: epidemiology and predictors. Br J Dermatol 2008; 158: 95-100.

17. Bilsborough J, Leung DY, Maurer M, et al. IL-31 is associated with cutaneous lymphocyte antigen-positive skin homing $\mathrm{T}$ cells in patients with atopic dermatitis. J Allergy Clin Immunol 2006; 117: 418-25.

18. Cornelissen C, Lüscher-Firzlaff J, Baron JM, Lüscher B. Signaling by IL-31 and functional consequences. Eur J Cell Biol 2012; 91: 552-66.

19. Nobbe S, Dziunycz P, Mühleisen B, et al. IL-31 expression by inflammatory cells is preferentially elevated in atopic dermatitis. Acta Derm Venereol 2012; 92: 24-8.

20. Sonkoly E, Muller A, Lauerma AI, et al. IL-31: a new link between $\mathrm{T}$ cells and pruritus in atopic skin inflammation. J Allergy Clin Immunol 2006; 117: 411-7.

21. Hawro T, Saluja R, Weller K, Altrichter S, Metz M, Maurer M. Interleukin-31 does not induce immediate itch in atopic dermatitis patients and healthy controls after skin challenge. Allergy 2014; 69: 113-7.

22. Dillon SR, Sprecher C, Hammond A, et al. Interleukin 31, a cytokine produced by activated $\mathrm{T}$ cells, induces dermatitis in mice. Nat Immunol 2004; 5: 752-60.

23. Le Saux S, Rousseau F, Barbier F, et al. Molecular dissection of human interleukin-31-mediated signal transduction through site-directed mutagenesis. J Biol Chem 2010; 285: 3470-7.
24. Kwak IS, Choi YH, Jang YC, Lee YK. Immunohistochemical analysis of neuropeptides (protein gene product 9.5, substance P and calcitonin gene-related peptide) in hypertrophic burn scar with pain and itching. Burns 2014; 40: 1661-7.

25. Varney VA, Hamid QA, Gaga M, et al. Influence of grass pollen immunotherapy on cellular infiltration and cytokine mRNA expression during allergen-induced late-phase cutaneous responses. J Clin Invest 1993; 92: 644-51.

26. Kasraie S, Niebuhr M, Baumert K, Werfel T. Functional effects of interleukin 31 in human primary keratinocytes. Allergy 2011; 66: $845-52$.

27. Nattkemper LA, Martinez-Escala ME, Gelman AB, et al. Cutaneous T-cell lymphoma and pruritus: the expression of IL-31 and its receptors in the skin. Acta Derm Venereol 2016; 96: 894-8.

28. Kasutani K, Fujii E, Ohyama S, et al. Anti-IL-31 receptor antibody is shown to be a potential therapeutic option for treating itch and dermatitis in mice. Br J Pharmacol 2014; 171: 5049-58.

29. Bando T, Morikawa Y, Komori T, Senba E. Complete overlap of interleukin-31 receptor $\mathrm{A}$ and oncostatin $\mathrm{M}$ receptor beta in the adult dorsal root ganglia with distinct developmental expression patterns. Neuroscience 2006; 142: 1263-71.

30. Steinhoff M, Bienenstock J, Schmelz M, Maurer M, Wei E, Bíró T. Neurophysiological, neuroimmunological, and neuroendocrine basis of pruritus. J Invest Dermatol 2006; 126: 1705-18.

31. Van Cromphaut I, Fumal I, Jacquemin D, Fissette J, Piérard GE. Skin barrier repair after contact burns: electrometric evaluation using the passive sustainable hydration test. J Environ Med 1999; 1: 47-50.

32. Vickery BP. Skin barrier function in atopic dermatitis. Curr Opin Pediatr 2007; 19: 89-93.

33. Singh B, Jegga AG, Shanmukhappa KS, et al. IL-31-driven skin remodeling involves epidermal cell proliferation and thickening that lead to impaired skin-barrier function. PLoS One 2016; 11: e0161877.

34. Niyonsaba F, Ushio H, Hara M, et al. Antimicrobial peptides human beta-defensins and cathelicidin LL-37 induce the secretion of a pruritogenic cytokine IL-31 by human mast cells. J Immunol 2010; 184: 3526-34.

35. Poindexter BJ, Bhat S, Buja LM, Bick RJ, Milner SM. Localization of antimicrobial peptides in normal and burned skin. Burns 2006; 32: 402-7.

36. Niyonsaba F, Nagaoka I, Ogawa H. Human defensins and cathelicidins in the skin: beyond direct antimicrobial properties. Crit Rev Immunol 2006; 26: 545-76.

37. Frohm M, Agerberth B, Ahangari G, et al. The expression of the gene coding for the antibacterial peptide LL-37 is induced in human keratinocytes during inflammatory disorders. J Biol Chem 1997; 272: 15258-63. 